\title{
The Diagnostic Value of Malondialdehyde, Superoxide Dismutase and Catalase Activity in Drug Naïve, First Episode, Non-Smoker Generalized Anxiety Disorder Patients
}

\author{
Ebru Fındıklı ${ }^{1}$, Mehmet Akif Camkurt ${ }^{2}$, Filiz İzci ${ }^{3}$, Mehmet Fatih Karaaslan ${ }^{1}$, Hüseyin Avni Fındıklı ${ }^{4}$, \\ Perihan Sümer ${ }^{5}$, Ergül Belge Kurutaş \\ Departments of ${ }^{1}$ Psychiatry and ${ }^{5}$ Biochemistry, Faculty of Medicine, Kahramanmaraş Sütçü İmam University, Kahramanmaraş, ${ }^{2}$ Department of \\ Psychiatry, Afşin State Hospital, Afşin, Kahramanmaraş, ${ }^{3}$ Department of Psychiatry, İstanbul Bilgi University, İstanbul, ${ }^{4}$ Department of Internal \\ Medicine, School of Medicine, Adıyaman University, Adıyaman, Turkey
}

\begin{abstract}
Objective: Generalized anxiety disorder (GAD) is a common anxiety disorder. Although lots of research done to reveal neurobiological basis of GAD, it is still unclear. Diagnosis of GAD depends on subjective complaints of patients, thus the need for a biological marker is constantly emerging. In this study, we aimed to investigate diagnostic value of malondialdehyde (MDA), superoxide dismutase (SOD) and catalase (CAT) in GAD.

Methods: We evaluated MDA, SOD, and CAT levels in peripheral blood of 46 patients and 45 controls. MDA was measured with Ohkawa's methods, SOD was measured with Fridovich method, and CAT was measured with Beutler's method.

Results: MDA was significantly increased in patients than controls, medians $4.05 \mathrm{nmol} / \mathrm{mg}$ and $1.71 \mathrm{nmol} / \mathrm{mg} \mathrm{re}-$ spectively, $p<0.001$; SOD and CAT activity was significantly decreased in patients than controls, medians of SOD were $159.07 \mathrm{U} / \mathrm{mg}$ and $301.87 \mathrm{U} / \mathrm{mg}$, $p<0.001$ respectively, medians for CAT were $138.47 \mathrm{U} / \mathrm{mg}$ and $160.60 \mathrm{U} / \mathrm{mg}$ respectively. We found high correlation between Hamilton Anxiety Rating Scale and SOD, MDA r values were 0.723 and 0.715 respectively, $p<0.001$ for both. Receiver operator characteristic (ROC) curve analysis showed high diagnostic performance for MDA and SOD, low diagnostic performance for CAT, areas under curve were 1.0, 1.0, and 0.648 respectively.

Conclusion: Our results reveal possible diagnostic value of MDA, less likely of SOD but not CAT. Future studies should investigate diagnostic value of oxidants and antioxidantn enzymes in larger samples and include diagnostic value of these parameters.
\end{abstract}

KEY WORDS: Malondialdehyde; Superoxide dismutase; Catalase; Generalised anxiety disorder; Oxidative; Biomarkers.

\section{INTRODUCTION}

Oxidative stress can be defined as an increase in oxidative parameters or a decline in antioxidant defense mechanisms. ${ }^{1)}$ Malondialdehyde (MDA) is the end product of lipid peroxidation that represents oxidation. Superoxide dismutase (SOD) and catalase (CAT) are antioxidant enzymes. They are responsible for eliminating free radicals like superoxide and hydrogen peroxide, and they stand for antioxidant defense mechanisms. ${ }^{2)}$

Received: March 8, 2016/Revised: April 3, 2016

Accepted: April 25, 2016

Address for correspondence: Mehmet Akif Camkurt, MD

Tel: +90-5064404400

E-mail: Dr.akif@gmail.com
Generalized anxiety disorder (GAD) is a common anxiety disorder with a prevalence of $5 \%$. Women tend to have GAD two times more often than men. Furthermore, other psychiatric disorders accompany GAD. ${ }^{3)}$ In spite of growing research focusing on the neurobiological, social, and psychological bases of GAD, its etiology is still unclear. ${ }^{4)}$ On the other hand, anxiety disorders impose a high burden on individuals' lives, and significant efforts are being made to find a biological marker in terms of prognosis and diagnosis. In the context of biological markers, peripheral blood tissue is a good candidate because of being easily accessible and feasible to investigate.

Until now, there has been considerable literature on bi-

(C) This is an Open-Access article distributed under the terms of the Creative Commons Attribution Non-Commercial License (http://creativecommons.org/licenses/by-nc/4.0) which permits unrestricted non-commercial use, distribution, and reproduction in any medium, provided the original work is properly cited. 
omarker research in psychiatry practice. Genetic, electrophysiological, inflammatory, and oxidative-antioxidant markers have been investigated to detect biomarkers. ${ }^{3,6-10)}$ Despite oxidative stress and antioxidant enzyme levels being easy to study in peripheral tissues, very little is known about their diagnostic value in GAD. Currently, only one study exists in this regard. Bulut et al.") investigated the diagnostic performance of paraoxonase activity in GAD. Furthermore, MDA, SOD, and CAT activity and their diagnostic values have been investigated in major depression patients. ${ }^{11)}$ Prolidase activity was investigated in two studies to evaluate its diagnostic value in bipolar disorder and schizophrenia. ${ }^{12,13)}$ Selek et al. ${ }^{14)}$ also studied the diagnostic performance of myeloperoxidase and CAT in bipolar disorder.

In a rat model, vitamin A was found to be anxiogenic due to its effects on the rat hippocampus. ${ }^{15)}$ Desrumaux et al. ${ }^{16)}$ showed that a deficiency of phospholipid transfer protein decreased vitamin E levels and resulted in anxiety. Overexpression of glyoxalase- 1 and glutathione reductase 1 is another anxiety-related finding in rats. ${ }^{17)}$ Although mounting data exist for oxidative stress in animal models of anxiety disorders, generation of these data to humans is still vague. In spite of being widely investigated in major depression and schizophrenia, few studies examined the role of oxidative stress in anxiety disorders. ${ }^{18,19)}$ MDA, SOD, and CAT levels have been a topic of interest in social phobia, obsessive compulsive disorder, and panic disorder. ${ }^{2,20-22)}$

As far as we know, poor data exist about the oxidative stress in anxiety disorders. Our current knowledge depends on a handful of studies reported by the same group. In our study, we aimed to investigate MDA in terms of oxidative stress and SOD and CAT regarding antioxidant enzymes. Furthermore, to the best of our knowledge, this is the first study investigating SOD and CAT levels and evaluating the diagnostic values of MDA, SOD, and CAT levels in GAD.

\section{METHODS}

\section{Participants}

Blood samples were collected from 46 patients and 45 healthy controls that were admitted to Department of Psychiatry in Kahramanmaraş University Teaching Hospital (Kahramanmaraş, Turkey). The Kahramanmaraş
University Ethical Committee approved our research (No. 138; October 2015). Written informed consent was obtained from patients and healthy controls that participated in the study. Drug-naïve, smoke-free, alcohol-free patients who met diagnostic criteria for GAD according to the Structured Clinical Interview for the Diagnostic and Statistical Manual of Mental Disorders 4th edition and had no comorbid psychiatric disorders were included. The Hamilton Anxiety Rating Scale (HAM-A) applied to all of the study participants. The control group also consisted of individuals without chronic medical or psychiatric conditions whose HAM-A scores were under 5. Both patients and controls were evaluated in terms of infection, allergic reaction, medical comorbidity, malnutrition, drug abuse, and antioxidant medication. Those who had one of these conditions were excluded from the study. The ages and genders of the groups were matched. We used strict exclusion criteria to obtain homogenous groups.

\section{CAT Activity}

CAT activities were determined by measuring the decrease in hydrogen peroxide concentration at $230 \mathrm{~nm}$ by the method of Beutler. ${ }^{23)}$ The assay medium consisted of 1 $\mathrm{mol} / \mathrm{L}$ Tris $\mathrm{HCl}-5 \mathrm{mmol} / \mathrm{L}$ disodium ethylenediamine tetraacetic acid (EDTA) buffer solution $(\mathrm{pH} 8.0), 1.0 \mathrm{~mol} / \mathrm{L}$ phosphate buffer solution (pH 7.0), and $10 \mathrm{mmol} / \mathrm{L} \mathrm{H}_{2} \mathrm{O}_{2}$. CAT activity was expressed as $\mathrm{U} / \mathrm{mg}$ protein.

\section{SOD Activity}

SOD activity was measured according to the method described by Fridovich. ${ }^{24)}$ This method employs xanthine and xanthine oxidase to generate superoxide radicals that react with p-iodonitrotetrazolium violet (INT) to form a red formazan dye that was measured at $505 \mathrm{~nm}$. The assay medium consisted of the $0.01 \mathrm{~mol} / \mathrm{L}$ phosphate buffer, a 3-cyclohexilamino-1-propanesulfonic acid (CAPS) buffer solution $(50 \mathrm{mmol} / \mathrm{L}$ CAPS, $0.94 \mathrm{mmol} / \mathrm{L}$ EDTA, saturated $\mathrm{NaOH})$ of $\mathrm{pH} 10.2$, solution of substrate $(0.05$ $\mathrm{mmol} / \mathrm{L}$ xanthine, $0.025 \mathrm{mmol} / \mathrm{L} \mathrm{INT}$ ), and $80 \mathrm{U} / \mathrm{L}$ xanthine oxidase. SOD activity was expressed as $\mathrm{U} / \mathrm{mg}$ protein.

\section{Measurement of Lipid Peroxidation}

The lipid peroxidation level in samples was expressed as MDA. It was measured according to the procedure of Ohkawa et al. ${ }^{25)}$ The reaction mixture contained $0.1 \mathrm{ml}$ of 
the sample, $0.2 \mathrm{ml}$ of $8.1 \%$ sodium dodecylsulfate, $1.5 \mathrm{ml}$ of $20 \%$ acetic acid, and $1.5 \mathrm{ml}$ of $0.8 \%$ aqueous solution of thiobarbituric acid. The mixture $\mathrm{pH}$ was adjusted to 3.5 and the volume was finally made up to $4.0 \mathrm{ml}$ with distilled water, and $5.0 \mathrm{ml}$ of the mixture of $n$-butanol and pyridine $(15: 1, v / v)$ were added. The mixture was shaken vigorously. After centrifugation at 3,220 $g$ for 10 minutes, the absorbance of the organic layer was measured at 532 $\mathrm{nm}$. MDA level was expressed as nmol/mg protein.

\section{Statistical Analysis}

Statistical analysis was performed using the Statistical Package for Social Sciences, ver. 11.5 (SPSS Inc., Chicago, IL, USA) and MedCalc ${ }^{\circledR}$ ver. 11.0.1 (MedCalc Software bvba, Ostend, Belgium). A $p$ value of less than 0.05 was considered statistically significant. The normality of continuous variables was assessed using Shapiro-Wilk's W-test.

Relationships between the categorical variables were evaluated using the chi-square test. To compare of mean differences for normally distributed continuous variables between the two groups, a Student's $t$ test was used. The Mann-Whitney $U$ test was used to compare the two groups when the assumption of normality was not fulfilled. While investigating associations of data, correlation coefficients and their significance were calculated with Spearman's test (for non-normally distributed variables) and Pearson's test (for normally distributed variables). A receiver operator characteristics (ROC) curve was plotted in order to find the cut-off point.

\section{RESULTS}

There were no differences between patients and controls in terms of age $(34.7 \pm 8.61,34.06 \pm 10.6, p=0.749$, respectively) and sex $(p=0.468)$. HAM-A scores were sig- nificantly higher in patients than controls (medians were 13 and 2 respectively, $p<0.001$ ). The average episode duration was 30.6 weeks for patients (Table 1).

MDA levels were significantly higher in patients than healthy controls (medians were $4.05 \mathrm{nmol} / \mathrm{mg}$ and 1.71 $\mathrm{nmol} / \mathrm{mg}$ respectively, $p<0.001$ ). The highest and lowest bounds for MDA in GAD patients were $5.62 \mathrm{nmol} / \mathrm{mg}$ and $2.77 \mathrm{nmol} / \mathrm{mg}$, respectively. The highest and lowest bounds for MDA in the control group were $2.47 \mathrm{nmol} / \mathrm{mg}$ and $1.10 \mathrm{nmol} / \mathrm{mg}$, respectively (Fig. 1). CAT levels were significantly lower in patients than in controls (medians were $138.47 \mathrm{U} / \mathrm{mg}$ and $160.60 \mathrm{U} / \mathrm{mg}$ respectively, $p=0.042$ ). SOD levels were significantly lower in patients than in controls (medians were $159.07 \mathrm{U} / \mathrm{mg}$ and 301.87 $\mathrm{U} / \mathrm{mg}, p<0.001$, respectively) (Table 2 ). The highest and lowest bounds for SOD in GAD patients were 178.35 $\mathrm{U} / \mathrm{mg}$ and $116.19 \mathrm{U} / \mathrm{mg}$, respectively. The highest and lowest bounds for SOD in the control group were 329.88 $\mathrm{U} / \mathrm{mg}$ and $213.53 \mathrm{U} / \mathrm{mg}$, respectively (Fig. 2).

While analyzing correlations, we found significant and

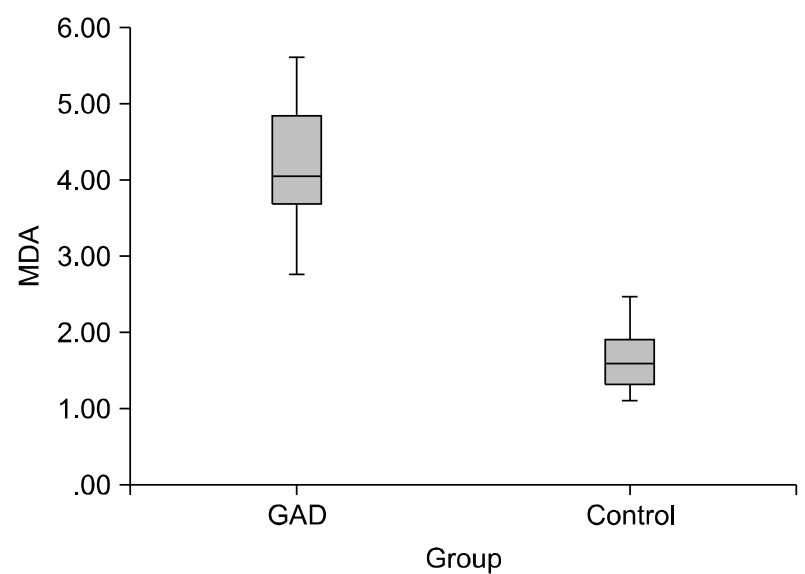

Fig. 1. Box plot graph for malondialdehyde (MDA), representing highest, lowest and mean values in both groups. GAD, generalized anxiety disorder.

Table 1. Clinical characteristics of patients

\begin{tabular}{lccr}
\hline \multicolumn{1}{c}{ Variable } & GAD $(\mathrm{n}=46)$ & Control $(\mathrm{n}=45)$ & $p$ value \\
\hline Gender (male/female) & $17 / 29$ & $21 / 24$ & 0.468 \\
Age $(\mathrm{yr})$ & $34.7 \pm 8.61$ & $34.06 \pm 10.6$ & 0.749 \\
HAM-A & $13.76 \pm 2.02$ & $2.93 \pm 2.03$ & $<0.001$ \\
Duration of episode $(\mathrm{wk})$ & $30.6 \pm 4.2$ & & \\
\hline
\end{tabular}

Values are presented as number only or mean \pm standard deviation.

There were no difference between patients an controls in terms of age and sex. HAM-A scores were significantly higher in patients than controls. Average duration of episode was 30.6 weeks for patients.

GAD, generalized anxiety disorder; HAM-A, Hamilton Anxiety Rating Scale. 
Table 2. Malondialdehyde (MDA), catalase (CAT), and superoxide dismutase (SOD) levels

\begin{tabular}{lccrr}
\hline & GAD $(\mathrm{n}=46)$ & Control $(\mathrm{n}=45)$ & $\mathrm{Z}$ value & $p$ value \\
\hline MDA $(\mathrm{nmol} / \mathrm{mg})$ & $4.14 \pm 0.73$ & $1.71 \pm 0.41$ & -8.218 & $<0.001$ \\
CAT $(\mathrm{U} / \mathrm{mg})$ & $143.43 \pm 27.37$ & $155.49 \pm 25.13$ & -2.033 & 0.042 \\
SOD $(\mathrm{U} / \mathrm{mg})$ & $157.06 \pm 16.32$ & $296.91 \pm 22.77$ & -8.218 & $<0.001$ \\
\hline
\end{tabular}

Values are presented as mean \pm standard deviation.

MDA was significantly increased in patients than controls, $p<0.001$. SOD and CAT activity was significantly decreased in patients than controls, $p<0.001$ and 0.042 respectively.

GAD, generalized anxiety disorder.

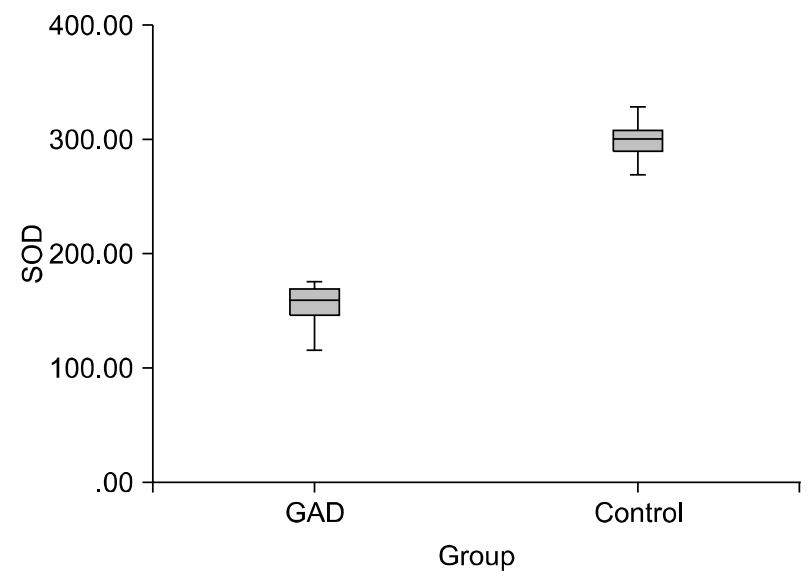

Fig. 2. Box plot graph for superoxide dismutase (SOD), representing highest, lowest and mean values in both groups.

GAD, generalized anxiety disorder.

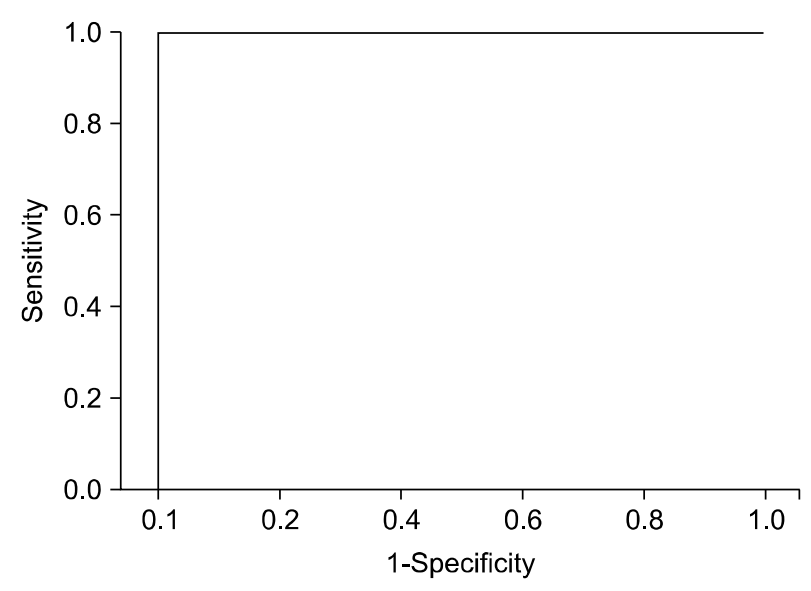

AUC

Test result variable: MDA

\begin{tabular}{|c|c|c|c|}
\hline \multirow{2}{*}{ Area } & Asymptotic Sig. & \multicolumn{2}{|c|}{ Asymptotic 95\% confidence interval } \\
\cline { 3 - 4 } & & Lower bound & Upper bound \\
\hline 1.000 & .000 & 1.000 & 1.000 \\
\hline
\end{tabular}

Fig. 3. Area under curve (AUC) was 1.0 for malondialdehyde (MDA). Cut-off point was detected as $2.77 \mathrm{nmol} / \mathrm{ml}$.

Sig, significance.

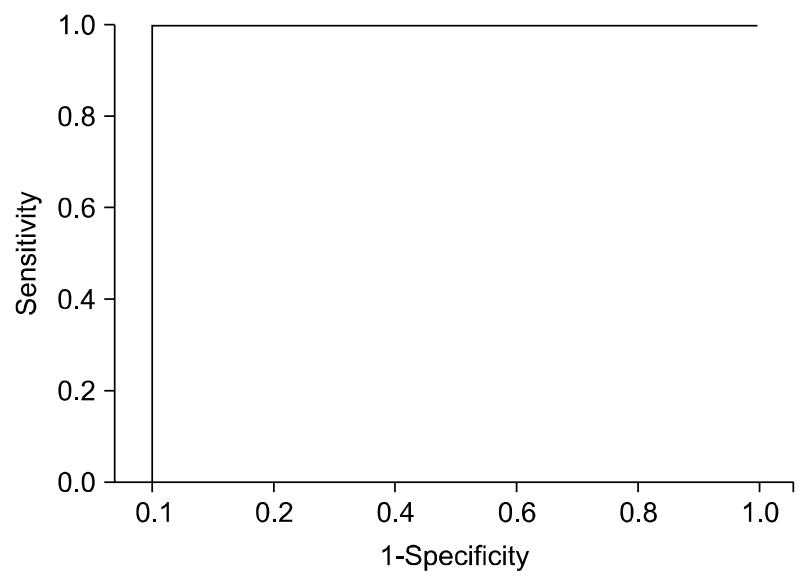

AUC

Test result variable: SOD

\begin{tabular}{|c|c|c|c|}
\hline Area & Asymptotic Sig. & \multicolumn{2}{|c|}{ Asymptotic 95\% confidence interval } \\
\cline { 3 - 4 } & & Lower bound & Upper bound \\
\hline 1.000 & .000 & 1.000 & 1.000 \\
\hline
\end{tabular}

Fig. 4. Area under curve $(A \cup C)$ was 1.0 for superoxide dismutase (SOD). Cut-off point was detected as cut-off point $178.35 \mathrm{U} / \mathrm{mg}$. Sig, significance.

high correlations between HAM-A scores and SOD levels $(\mathrm{r}=0.723, p<0.001)$, HAM-A scores, and MDA levels $(\mathrm{r}=0.715, p<0.001)$, and a significant but low correlation between HAM-A scores and CAT levels $(r=0.255$, $p=0.015)$.

A ROC curve was plotted for MDA, SOD and CAT levels. Areas under the curve were 1.000 for MDA ( $p$ $<0.001), 1.000$ for SOD $(p<0.001)$, and 0.648 for CAT $(p=0.042)$. These findings indicate that MDA and SOD levels are diagnostic. The cut-off point was $178.35 \mathrm{U} / \mathrm{mg}$ for SOD, and all of the patient group SOD levels were under the cut-off point. For MDA, the cut-off point was 2.77 $\mathrm{nmol} / \mathrm{mg}$, and all of the patient group MDA levels were above the cut-off point. The sensitivity and specificity of MDA and SOD were $100 \%$. The positive predictive value (PPV) and negative predictive value (NPV) were also 
100\% (Figs. 3, 4).

\section{DISCUSSION}

Significant findings of our study are as follows; increased MDA and decreased SOD and CAT levels in GAD patients. MDA represents increased oxidation in GAD, and decreased SOD and CAT levels point out diminished antioxidant mechanisms. Decreased SOD and increased MDA levels were diagnostic for GAD. PPV and NPV were $100 \%$. Sensitivity and specificity were also $100 \%$ for MDA and SOD. A high correlation was observed between HAM-A scores and MDA and SOD.

MDA levels have been investigated in obsessive compulsive disorder (OCD), social phobia (SP), and post-traumatic stress disorder (PTSD). Almost all of the studies reported increased MDA levels in patients except for PTSD. ${ }^{2,20-22,26,27)}$ Tezcan et al. ${ }^{20)}$ reported that the MDA levels of PTSD patients and healthy controls were similar. Although our study is the first study investigating MDA levels in GAD patients, based on previous knowledge, we interpret that MDA increase is a common finding in anxiety disorders. This conjecture helps us to understand the neurobiology of anxiety, taking into account that brain tissue contains high amounts of lipids, which is a substrate for peroxidation; increased oxidation thus makes the brain vulnerable to oxidation. ${ }^{28)}$

SOD is the enzyme that catalyzes the conversion of superoxide anion radicals $(\mathrm{O} 2 \bullet-)$ to hydrogen peroxide and molecular oxygen, functioning as a controller of cellular reactive oxygen species levels. ${ }^{29)}$ Past reports denote increased SOD levels in patients with OCD and SP; however, we found that SOD levels were significantly decreased in GAD patients. ${ }^{21,27)}$ We propose two possible explanations for this situation. First, decreased SOD levels could be a trait of GAD, but not OCD or SP. Second, increased SOD activity is neither a consistent finding nor a marker for anxiety disorders. As supporting our second hypothesis, inconsistent SOD levels have been reported in patients with different stages of major depression. ${ }^{11,30-32)}$ As mentioned above, because of this inconsistency, we do not think that SOD level is a reliable marker in anxiety disorders. However, further studies should include larger patient groups from different anxiety disorders and more homogenous groups to detect whether SOD activity could be a biomarker. Additionally, decreased SOD ac- tivity is more likely to be associated with anxiety by causing vulnerability to oxidative stress.

CAT is a crucial enzyme for antioxidant mechanisms and decomposes hydrogen peroxide into water and oxygen. ${ }^{33)}$ Among anxiety disorders, CAT is reported to be increased in OCD and SP, but unchanged in PTSD. ${ }^{20,22,27)}$ However we found that CAT is decreased in GAD. Although increased MDA levels seem to be consistent among all anxiety disorders, this consistency is missing for SOD and CAT activity. In addition, this inconsistency is probably due to only one group's reported studies. This field of research needs reports from diverse groups and laboratories. Although our results are different from previous reports, we believe that the hypothesis that antioxidant mechanisms are diminished in anxiety disorders is more appropriate, as revealed by our results. While there are numerous factors related to anxiety, oxidative stress itself takes an important part separately.

High correlation values constitute an important part of our findings. The correlation coefficient is shown with the ' $r$ ' symbol. An $r$ value $\leq 0.35$ represents low or weak correlation, between 0.36 and 0.67 shows moderate correlation, 0.68 to 0.90 shows high correlation, and 0.90 to 1.0 shows very high correlation. ${ }^{34)}$ The $r$ values in our study, 0.715 (between MDA and HAM-A score) and 0.723 (between SOD and HAM-A score), are the highest values reported thus far. Correlations between anxiety disorders and anxiety scales have been presented before. Atmaca et al. ${ }^{21)}$ denoted a significant correlation between Liebowitz Social Anxiety Scale and SOD or CAT levels ( $r=0.55$ and $r=0.61$, respectively). Despite not reporting an $r$ value, Kuloglu et al. ${ }^{27)}$ found a significant correlation between depression scores and MDA or SOD levels. In PTSD, a significant correlation was found between Clinician Administered PTSD Scale and SOD levels $(r=0.55)$ or MDA levels $(r=0.41)$, and a significant correlation was reported between the duration of PTSD and SOD levels $(r=0.52)$ and MDA levels $(r=0.32){ }^{20)} \mathrm{A}$ review of previous data denotes important correlations between SOD, CAT, and MDA levels and disease status. We believe that a high correlation coefficient forms a basis for the detection of biomarkers. Further studies should investigate different anxiety disorders in terms of correlations between oxidants, antioxidants, and disease severity.

To the best of our knowledge, our study is the first study investigating the diagnostic value of antioxidants and oxi- 
dative parameters with a ROC curve in GAD. In ROC curve analysis, diagnostic accuracy is measured according to the area under the curve (AUC). The accuracy of the ROC-AUC test is as follows: 0.9 to 1 , excellent; 0.8 to 0.9 , good; 0.7 to 0.8 , fair; 0.6 to 0.7 , poor; and <0.6, not useful. $^{35)}$ The AUCs for MDA, SOD, and CAT were 1.0, 1.0 , and 0.648, respectively. MDA and SOD levels represent excellent diagnostic value according to our results. As far as we know, there are few studies evaluating the diagnostic potential of oxidant-antioxidants. Bulut et al. ${ }^{1)}$ reported paraoxonase to be a diagnostic marker for GAD (AUC, 0.980). In addition, Güneş et al. ${ }^{12)}$ found very high diagnostic performance for prolidase in schizophrenia patients using antipsychotic treatment (AUC, 1.0). Selek et al. ${ }^{13)}$ pointed out a high diagnostic value for prolidase; AUC, 0.989. They also propounded a diagnostic value of CAT for bipolar disorder (AUC, 0.989). ${ }^{14)}$ Sensitivity, specificity, and NPV and PPV values were $100 \%$ for MDA and SOD levels. Although our results show excellent diagnostic value, we do not interpret these data as a discovery of a new biomarker. We consider that MDA levels may have a great potential to be a biomarker for anxiety disorders. As we explained above, an increase of MDA is common and consistent in anxiety disorders. Besides, there is a correlation between MDA levels and disease status, as shown in several studies as well as ours. Despite finding a high diagnostic value for SOD, we think that SOD is not a reliable marker for anxiety disorders. By this time, increased, decreased, and unchanged SOD levels have been reported in anxiety disorders. Because of the incoherent results, the diagnostic value of SOD should be taken into account carefully.

There are some limitations of our study. First, we did not collect blood samples after treatment to investigate the effects of antidepressant treatment on diagnostic performance because of the study's cross-sectional design. The sample size was relatively small, and future studies should be performed in larger samples. On the other hand, the homogeneity of groups is the main strength of our research.

In conclusion, we found that MDA levels were significantly increased and SOD and CAT levels were significantly decreased in GAD patients. Furthermore, we found high diagnostic values for MDA and SOD levels, but we think that MDA levels are more reliable in terms of being a biomarker. These findings should be considered preliminary and needing verification by further studies. Our results should also be considered preliminary and needing confirmation by future studies.

\section{REFERENCES}

1. Bulut M, Selek S, Bez Y, Karababa IF, Kaya MC, Gunes M, et al. Reduced PON1 enzymatic activity and increased lipid hydroperoxide levels that point out oxidative stress in generalized anxiety disorder. J Affect Disord 2013;150:829-833.

2. Camkurt MA, Findıklı E, Bakacak M, Karaaslan MF, Tolun Fl, Tuman TC. Depression in pregnancy is associated with decreased g/utathione peroxidase activity in fetal cord blood. J Psychiatr Res 2016;79:57-60.

3. Park JS, Lim S, Ha J, Lee MS, Oh KS. Lack of association between brain-derived neurotrophic factor gene val66met polymorphisms and generalized social anxiety disorder in Korean population. Clin Psychopharmacol Neurosci 2011;9:129133.

4. Wittchen HU, Carter RM, Pfister H, Montgomery SA, Kessler RC. Disabilities and quality of life in pure and comorbid generalized anxiety disorder and major depression in a national survey. Int Clin Psychopharmacol 2000;15:319-328.

5. Biomarkers Definitions Working Group. Biomarkers and surrogate endpoints: preferred definitions and conceptual framework. Clin Pharmacol Ther 2001;69:89-95.

6. Nurjono M, Lee J, Chong SA. A review of brain-derived neurotrophic factor as a candidate biomarker in schizophrenia. Clin Psychopharmacol Neurosci 2012;10:61-70.

7. Ma SL, Lam LC. Panel of genetic variations as a potential non-invasive biomarker for early diagnosis of Alzheimer's disease. Clin Psychopharmacol Neurosci 2011;9:54-66.

8. Camkurt MA, Karababa İF, Erdal ME, Bayazıt H, Kandemir S, Kandemir $\mathrm{H}$, et al. Investigation of dysregulation of several microRNAs in peripheral blood of schizophrenia patients. Clin Psychopharmacol Neurosci 2016;14:256-260.

9. Al-Amin MM, Nasir Uddin MM, Mahmud Reza H. Effects of antipsychotics on the inflammatory response system of patients with schizophrenia in peripheral blood mononuclear cell cultures. Clin Psychopharmacol Neurosci 2013;11: 144-151.

10. Steiger A, Kimura M. Wake and sleep EEG provide biomarkers in depression. J Psychiatr Res 2010;44:242-252.

11. Camkurt MA, Findıklı E, İzci F, Kurutaş EB, Tuman TC. Evaluation of malondialdehyde, superoxide dismutase and catalase activity and their diagnostic value in drug naive, first episode, non-smoker major depression patients and healthy controls. Psychiatry Res 2016;238:81-85.

12. Güneş $M$, Bulut $M$, Demir S, İbiloğlu $A O$, Kaya MC, Atl 1 A, et al. Diagnostic performance of increased prolidase activity in schizophrenia. Neurosci Lett 2016;613:36-40.

13. Selek S, Altindag A, Saracoglu G, Celik H, Aksoy N. Prolidase activity and its diagnostic performance in bipolar disorder. $J$ Affect Disord 2011;129:84-86. 
14. Selek S, Altindag A, Saracoglu G, Aksoy N. Oxidative markers of myeloperoxidase and catalase and their diagnostic performance in bipolar disorder. J Affect Disord 2015; 181:92-95.

15. de Oliveira MR, Silvestrin RB, Mello E Souza T, Moreira JC. Oxidative stress in the hippocampus, anxiety-like behavior and decreased locomotory and exploratory activity of adult rats: effects of sub acute vitamin A supplementation at therapeutic doses. Neurotoxicology 2007;28:1191-1199.

16. Desrumaux C, Risold PY, Schroeder H, Deckert V, Masson D, Athias A, et al. Phospholipid transfer protein (PLTP) deficiency reduces brain vitamin $E$ content and increases anxiety in mice. FASEB J 2005; 19:296-297.

17. Hovatta I, Tennant RS, Helton R, Marr RA, Singer O, Redwine $\mathrm{JM}$, et al. Glyoxalase 1 and g/utathione reductase 1 regulate anxiety in mice. Nature 2005;438:662-666.

18. Lopresti AL, Maker GL, Hood SD, Drummond PD. A review of peripheral biomarkers in major depression: the potential of inflammatory and oxidative stress biomarkers. Prog Neuropsychopharmacol Biol Psychiatry 2014;48:102-111.

19. Grignon S, Chianetta JM. Assessment of malondialdehyde levels in schizophrenia: a meta-analysis and some methodological considerations. Prog Neuropsychopharmacol Biol Psychiatry 2007;31:365-369.

20. Tezcan E, Atmaca M, Kuloglu M, Ustundag B. Free radicals in patients with post-traumatic stress disorder. Eur Arch Psychiatry Clin Neurosci 2003;253:89-91.

21. Atmaca M, Tezcan E, Kuloglu M, Ustundag B, Tunckol H. Antioxidant enzyme and malondialdehyde values in social phobia before and after citalopram treatment. Eur Arch Psychiatry Clin Neurosci 2004;254:231-235.

22. Atmaca M, Kuloglu M, Tezcan E, Ustundag B. Antioxidant enzyme and malondialdehyde levels in patients with social phobia. Psychiatry Res 2008;159:95-100.

23. Beutler E. Red cell metabolism: a manual of biochemical methods. New York, NY:Grune \& Stratton;1984.

24. Fridovich I. Superoxide radical and superoxide dismutases. Acc Chem Res 1972;5:321-326.
25. Ohkawa H, Ohishi N, Yagi K. Assay for lipid peroxides in animal tissues by thiobarbituric acid reaction. Anal Biochem 1979;95:351-358.

26. Kuloglu M, Atmaca M, Tezcan E, Ustundag B, Bulut S. Antioxidant enzyme and malondialdehyde levels in patients with panic disorder. Neuropsychobiology 2002;46:186-189.

27. Kuloglu M, Atmaca M, Tezcan E, Gecici O, Tunckol H, Ustundag B. Antioxidant enzyme activities and malondialdehyde levels in patients with obsessive-compulsive disorder. Neuropsychobiology 2002;46:27-32.

28. Ng F, Berk M, Dean O, Bush Al. Oxidative stress in psychiatric disorders: evidence base and therapeutic implications. Int J Neuropsychopharmacol 2008;11:851-876.

29. Perry JJ, Shin DS, Getzoff ED, Tainer JA. The structural biochemistry of the superoxide dismutases. Biochim Biophys Acta 2010;1804:245-262.

30. Bilici M, Efe H, Köroğlu MA, Uydu HA, Bekaroğlu M, Değer O. Antioxidative enzyme activities and lipid peroxidation in major depression: alterations by antidepressant treatments. J Affect Disord 2001;64:43-51.

31. Herken H, Gurel A, Selek S, Armutcu F, Ozen ME, Bulut M, et al. Adenosine deaminase, nitric oxide, superoxide dismutase, and xanthine oxidase in patients with major depression: impact of antidepressant treatment. Arch Med Res 2007;38:247252.

32. Bajpai A, Verma AK, Srivastava M, Srivastava R. Oxidative stress and major depression. I Clin Diagn Res 2014;8: CCO4-CCO7.

33. Alpak G, Selek S, Bulut M, Bülbul F, Ünal A, Vırıt O, et al. High catalase and low thiol levels in adult-ADHD patients. Klinik Psikofarmakoloji Bülteni-Bull Clin Psychopharmacol 2014;24:128-134.

34. Taylor R. Interpretation of the correlation coefficient: a basic review. J Diag Med Sonography 1990;6:35-39.

35. Kim JW, Lee YS, Han DH, Min KJ, Lee J, Lee K. Diagnostic utility of quantitative EEG in un-medicated schizophrenia. Neurosci Lett 2015;589:126-131. 